\title{
Surgical Approach to Transverse Colon Cancer: Analysis of Current Practice and Oncological Outcomes Using the National Cancer Database
}

\author{
Jacopo Crippa, M.D. ${ }^{1}$ Fabian Grass, M.D. ${ }^{1}$ Pietro Achilli, M.D. ${ }^{1}$ \\ Kevin T. Behm, M.D. ${ }^{1}$ Kellie L. Mathis, M.D. ${ }^{1}$ Courtney N. Day, B.S. ${ }^{2}$ \\ William S. Harmsen, M.S. ${ }^{2}$ Giulio M. Mari, M.D. ${ }^{1} \bullet$ David W. Larson, M.D., M.B.A. ${ }^{1}$ \\ 1 Colon and Rectal Surgery, Mayo Clinic, Rochester, Minnesota \\ 2 Department of Statistics and Probability, Mayo Clinic, Rochester, Minnesota
}

BACKGROUND: Surgical treatment for transverse colon cancer involves either extended colectomy or segmental resection, depending on the location of the tumor and surgeon perspective. However, the oncological safety of segmental resection has not yet been established in large cohort studies.

OBJECTIVE: This study aims to compare segmental resection versus extended colectomy for transverse colon cancer in terms of oncological outcomes.

DESIGN: This was a retrospective cohort study.

SETTINGS: This study was conducted using a nationwide cohort.

PATIENTS: A total of 66,062 patients who underwent colectomy with curative intent for transverse stage I to III adenocarcinoma were identified in the National Cancer Database (2004-2015).

MAIN OUTCOME MEASURES: Patients were divided in 2 groups based on the type of surgery received (extended versus segmental resection). The primary outcome was overall survival. Secondary outcomes were 30 - and 90-day mortality, length of hospital stay, and readmission rate within 30 days of surgical discharge.

RESULTS: Extended colectomy was performed in 44,417 (67.2\%) patients, whereas 21,645 (32.8\%) patients

Funding/Support: None reported.

Financial Disclosures: None reported.

Correspondence: David W. Larson, M.D., M.B.A., Chair of Colorectal Surgery, Mayo Clinic, 200 First St SW, Rochester, MN 55905. E-mail: Larson.David2@mayo.edu

Dis Colon Rectum 2021; 64: 284-292

DOI: $10.1097 /$ DCR.0000000000001887

(C) The ASCRS 2021 underwent segmental resection. Extended colectomy was associated with lower survival at multivariate analysis (HR, 1.07; 95\% CI, 1.04-1.10; $p<0.001$ ). The subgroup analysis showed that extended resection was independently associated with poorer survival in mid transverse colon cancers (HR, 1.08; 95\% CI, 1.04-1.12; $p<0.001)$ and in stage III tumors (HR, 1.11;95\% CI, $1.04-1.18 ; p<0.001)$. The number of at least 12 harvested lymph nodes was an independent predictor of improved survival in both overall and subgroup analyses.

LIMITATIONS: This study was limited by its retrospective design.

CONCLUSION: Extended colectomy was not associated with a survival advantage compared with segmental resection. On the contrary, extended colectomy was associated with slightly poorer survival in mid transverse cancers and locally advanced tumors. Segmental resection was found to be safe when appropriate margins and adequate lymph node harvest were achieved. See Video Abstract at http://links.lww.com/DCR/B454.

\section{ABORDAJE QUIRÚRGICO DEL CÁNCER DE COLON TRANSVERSO: ANÁLISIS DE LA PRÁCTICA ACTUAL Y LOS RESULTADOS ONCOLÓGICOS UTILIZANDO LA BASE DE DATOS NACIONAL DE CÁNCER}

ANTECEDENTES: El tratamiento quirúrgico para el cáncer de colon transverso implica colectomía extendida o resección segmentaria, según la ubicación del tumor y la perspectiva del cirujano. Sin embargo, la seguridad oncológica de la resección segmentaria aún no se ha establecido en estudios de cohortes grandes.

OBJETIVO: Este estudio tiene como objetivo comparar la resección segmentaria versus la colectomía extendida para el cáncer de colon transverso en términos de resultados oncológicos. 
DISEÑO: Este fue un estudio de cohorte retrospectivo.

ESCENARIO: Este estudio se realizó utilizando una cohorte a nivel nacional.

PACIENTES: Un total de 66,062 pacientes que se sometieron a colectomía con intención curativa por adenocarcinoma de colon transverso en estadio I-III fueron identificados en la Base de Datos Nacional del Cáncer (2004-2015).

PRINCIPALES MEDIDAS DE RESULTADO: Los pacientes se dividieron en dos grupos según el tipo de cirugía recibida (resección extendida versus resección segmentaria). El resultado primario fue la supervivencia global. Los resultados secundarios fueron la mortalidad a los 30 y 90 días, la duración de la estancia hospitalaria y la tasa de reingreso dentro de los 30 días posteriores al alta quirúrgica.

RESULTADOS: Se realizó colectomía extendida en 44,417 $(67.2 \%)$ casos, mientras que 21,645 (32.8\%) pacientes fueron sometidos a resección segmentaria. La colectomía extendida se asoció con una menor supervivencia en el análisis multivariado (HR 1.07 IC 95\% 1.04-1.10; $p<0.001)$. El análisis de subgrupos mostró que la resección extendida se asoció de forma independiente con una menor supervivencia en los cánceres de colon transverso medio (HR 1.08 IC 95\% 1.04-1.12; $p<0.001$ ) $\mathrm{y}$ en tumores en estadio III (HR 1.11 IC 95\% 1.04-1.18; $p<0.001)$. Un número de al menos 12 ganglios linfáticos cosechados fue un predictor independiente de una mejor supervivencia en los análisis general y de subgrupos.

LIMITACIONES: Este estudio estuvo limitado por su diseño retrospectivo.

CONCLUSIÓN: La colectomía extendida no se asoció con una ventaja de supervivencia en comparación con la resección segmentaria. Por el contrario, la colectomía extendida se asoció con una supervivencia levemente menor en cánceres de colon transverso medio y tumores localmente avanzados. Se encontró que la resección segmentaria es segura cuando se logran los márgenes apropiados y la cosecha adecuada de ganglios linfáticos. Consulte Video Resumen en http://links.lww.com/DCR/ B454. (Traducción-Dr. Jorge Silva Velazco)

KEY WORDS: Oncological outcomes; Overall survival; Surgical approach; Transverse colon cancer.

$\mathrm{T}$ he transverse colon originates from 2 distinct embryologic development planes, the midgut and the hindgut. ${ }^{1}$ The presence of a midline vascularization and variable lymphatic drainage patterns prevent surgeons from defining a standard operative approach to transverse colon cancer and represent a challenge for proper oncological resection. ${ }^{2}$
With less than $10 \%$ of all colon cancers, the transverse colon is an uncommon site for large-bowel cancer. ${ }^{3}$ Because of frequent exclusion from clinical trials, transverse cancer represents the least studied site for colon cancer and lacks description of technical details and surgical and oncological outcome. Some studies found higher complication rates associated with resection of transverse colon cancer compared with other colectomies ${ }^{4,5}$ and poorer long-term survival compared with left-sided tumors. ${ }^{6}$

Although the surgical approach to right- and left-sided tumors is standardized, both segmental and extended colectomy represent surgical options for transverse cancer. There is a lack of consensus on the preferred technical approach for transverse colon cancer and the potential impact on long-term survival. The choice of procedure seems to rely on potentially biased principles such as the patient's anatomy, tumor size, or surgeon preference. ${ }^{7}$ Previous literature revealed no difference in survival based on the extent of colonic resection. ${ }^{8,9}$ Nevertheless, this has not yet been confirmed by large-scale studies.

Our hypothesis was that segmental resection could be used as a safe and feasible approach to transverse cancer. For this reason, we investigated current surgical practice regarding transverse colon cancer and its influence on long-term survival by querying the American College of Surgeons National Cancer Database (NCDB). The aim of this study was to compare segmental resection versus extended colectomy for transverse colon cancer in terms of oncological outcomes.

\section{PATIENTS AND METHODS}

The present study reports a retrospective analysis of data collected from the NCDB. The NCDB is a nationwide hospital-based data set collecting data of more than $70 \%$ of newly diagnosed cancers in the United States. Data derive from more than 1500 accredited (Commission on Cancer (CoC) accreditation) facilities with the aim to track and analyze patients with malignant neoplastic diseases. The CoC accreditation standards require an annual 90\% followup rate for all living, eligible, analytic patients diagnosed within the last 5 years and an $80 \%$ follow-up for all eligible analytic cases from the cancer registry's reference date. ${ }^{10}$

Data were obtained through the spring 2018 participant user files application, which provided information on adult ( $\geq 18$ years) patients who were diagnosed with transverse colon cancer from 2004 through 2015.

This study aimed to investigate different surgical approaches to proximal, mid, and distal transverse colon cancer and to analyze their effect on overall survival (OS). Secondary outcomes were 30- and 90-day mortality, length of hospital stay, and readmission rate within 30 days of surgical discharge.

Patients who underwent colectomy with curative intent for proximal (including hepatic flexure), mid or 
distal (including splenic flexure) stage I to III adenocarcinoma, recorded in the International Classification of Diseases for Oncology, Third Edition as code C184, C183, and $\mathrm{C} 185$ were included. C184 was considered as mid transverse colon (MTC), C183 as proximal transverse colon (PTC), and C185 as distal transverse colon (DTC). Exclusion criteria were stage IV disease as defined by the American Joint Committee on Cancer, histology other than adenocarcinoma, and patients who did not undergo surgery as primary treatment. Analysis was restricted to patients with an initial diagnosis of colon cancer only (participant user file Sequence Number 00, 01) to avoid overlap and confounding outcomes with patients who may have been diagnosed and treated for a separate malignancy. Patients diagnosed in 2015 were excluded from the survival analysis because NCDB does not provide followup data for these patients in the examined population. Both demographic data and specific cancer characteristics were included in the analysis. ${ }^{11}$

Patients were divided into 2 groups: those who underwent a segmental resection, represented by the North American Association of Central Cancer Registries procedure code 30, and those who underwent an extended colectomy, North American Association of Central Cancer Registries code 40. Extended colectomy is defined as "total right or left colon and a portion of transverse colon," whereas segmental resection refers to colectomy limited to 1 segment of the transverse colon (proximal, mid, or distal).

\section{Statistical Analysis}

Differences in demographics and cancer characteristics were assessed by using the Wilcoxon rank-sum test for continuous variables and the $\chi^{2}$ test for categorical variables. Given the large sample size that the NCDB usually allows, a statistically significant difference is expected for every baseline characteristic. Unadjusted probability of surviving from the time of surgery to death or last follow-up was estimated using the Kaplan-Meier method. Cox proportional hazards regression models were used to assess variable associations with patient survival. Given the large number of patients in the data set, multivariable Cox models include variables identified as clinically relevant. Models were fit overall as well as stratified by primary site. A subgroup analysis with patients who have stage III colon cancer was also performed. SAS version 9.4 was used for analyses, and $p$ values of $<0.05$ were considered statistically significant.

\section{RESULTS}

A total of 66,062 patients were included in the study, with dropouts detailed in the flowchart in Figure 1. Extended colectomy was performed in 44,417 (67.2\%) cases, whereas a segmental resection was performed in 21,645 $(32.8 \%)$ cases. Table 1 reports demographics and clinical characteristics according to procedure type (extended vs segmental). Table 2 displays cancer characteristics and pathological specifics. The median number of harvested lymph nodes was higher for extended colectomies (18 (interquartile range: $13-25)$ vs 14 (interquartile range: $10-20 ; p<0.001)$. Extended colectomy was the preferred approach for PTC (86.6\%), MTC (60.1\%), and DTC (58.4\%), with a negative trend as the distance of the tumor from the ileocecal valve increased.

There was no statistically significant difference in 30-day and 90-day mortality (Table 3). Unplanned hospital readmissions were higher for patients who underwent extended colectomy ( $6.0 \%$ vs $5.4 \% ; p=0.007)$.

A total of 59,493 patients were included in the survival analysis. Overall median follow-up was 73 (43-105) months. Median follow-up for patients in the MTC, PTC, and DTC subgroups was 71 (42-104), 75 (45-108), and 73 (44-105) months. At unadjusted survival analysis, the 5 -year survival rate of patients who underwent extended colectomy was similar to the 5 -year survival rate of patients who received segmental colectomy $(40.7 \%$ and $41.3 \%$; $p=0.34$ ). Figure 2 illustrates Kaplan-Meier curves for OS according to surgical approach.

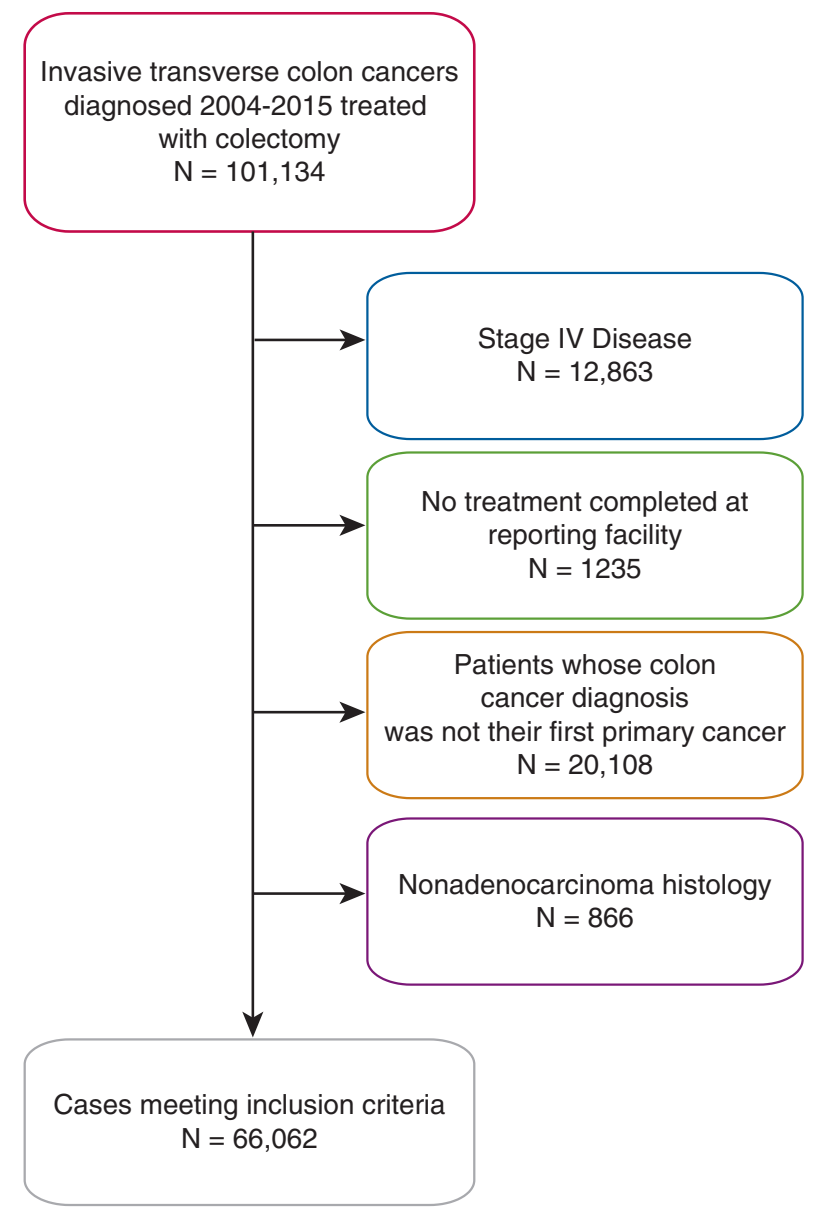

FIGURE 1. Flow chart of included patients. 
TABLE 1. Demographics and clinical characteristics among procedure types

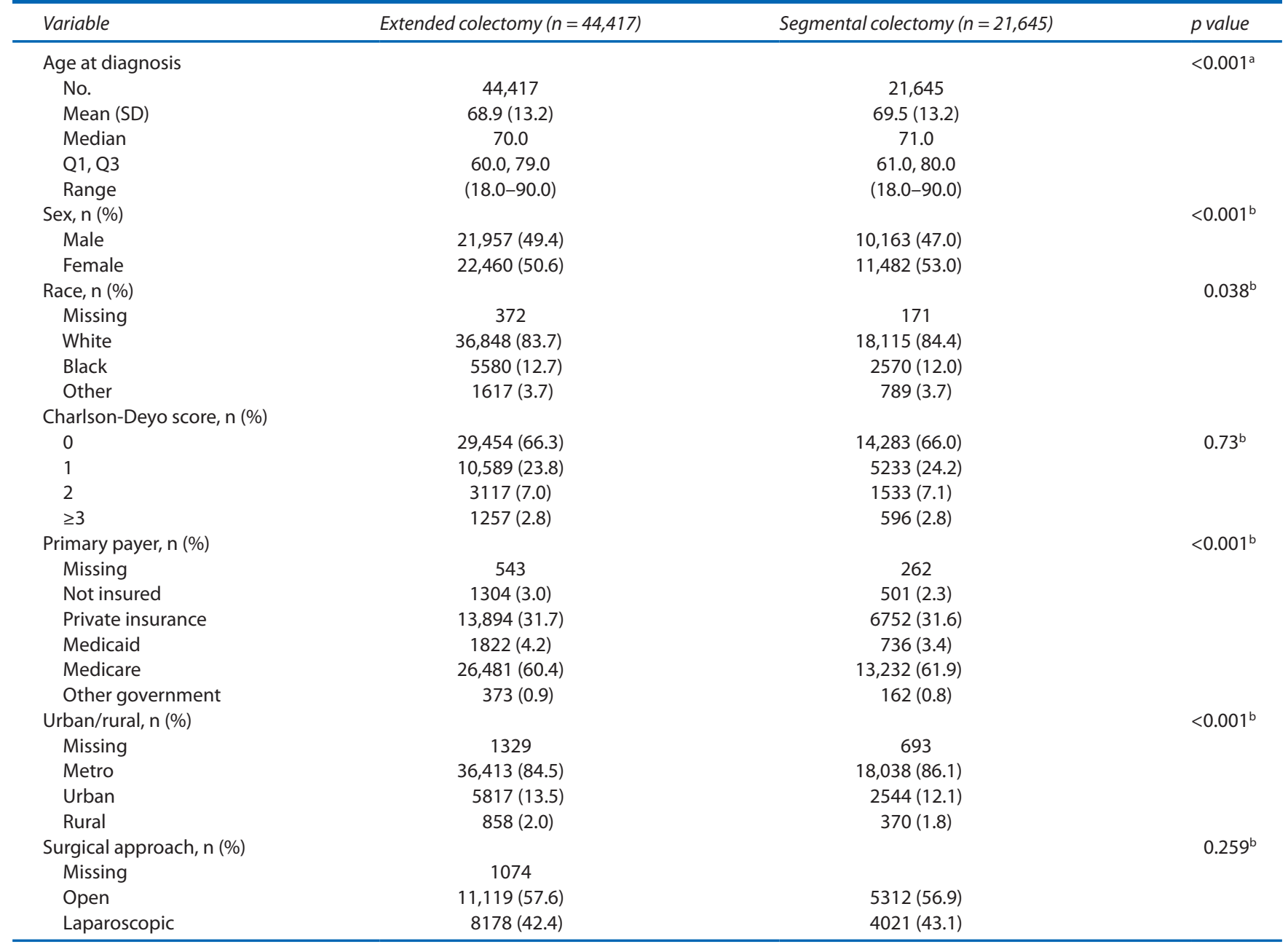

aWilcoxon rank-sum test.

${ }^{\mathrm{b}}$ Chi-square test.

Figure 3 reports the multivariable model for all transverse colon cancers. Older age, higher tumor grade, advanced disease stage, positive surgical margin, and omission of adjuvant treatment were associated with worse survival. After adjusting for covariates, extended colectomy for transverse colon cancer was associated with lower survival (HR, 1.07; 95\% CI, 1.04-1.10; $p<0.001$ ).

In the subgroup analysis of specific tumor locations, extended resection was independently associated with poorer survival in MTCs (HR, 1.08; 95\% CI, 1.04--1.12; $p<0.001$ ). The number of at least 12 harvested lymph nodes was an independent predictor of improved survival in both overall and subgroup analyses (HR, $0.80 ; 95 \% \mathrm{CI}$, $0.77-0.82 ; p<0.001$ for overall analysis) (Fig. 3, Table 4).

No difference in survival estimates between segmental resection and extended colectomy was revealed in the subgroup of patients with stage III transverse colon cancer $(\mathrm{n}=10,049)(5$-year OS: $58 \%$ vs $56 \%$; $p=0.51)$. After multivariable adjustment (Table 4 ), extended colectomy was associated with poorer survival (HR, 1.11;95\% CI, $1.04-1.18 ; p<0.001)$ in this specific subgroup.

\section{DISCUSSION}

The present retrospective analysis of a validated national cancer database was performed to investigate the impact of the extent of surgical resection of primary transverse colon cancer on long-term survival. This is the first NCDB investigation on this topic and represents the largest cohort yet published. Overall, similar outcomes between the 2 surgical approaches were identified, with slightly worse survival after extended colectomy in mid transverse cancers. Despite higher lymph node yield and an associated improved survival with high nodal counts, extended resection did not improve overall survival. With similar short-term mortality and long-term survival, the data support either surgical approach assuming adequate lymph node yield $(\geq 12)$. 
TABLE 2. Cancer characteristics among procedure types

\begin{tabular}{|c|c|c|c|}
\hline Variable & Extended colectomy $(n=44,417)$ & Segmental colectomy $(n=21,645)$ & pvalue \\
\hline \multicolumn{3}{|l|}{ Primary site, n (\%) } & $<0.001^{\mathrm{b}}$ \\
\hline Proximal transverse & $16,084(36.2)$ & $2481(11.5)$ & \\
\hline Medial transverse & $21,142(47.6)$ & $14,041(64.9)$ & \\
\hline Distal transverse & $7191(16.2)$ & $5123(23.7)$ & \\
\hline \multicolumn{3}{|l|}{ Grade, n (\%) } & $<0.001^{\mathrm{b}}$ \\
\hline Missing & 1320 & 688 & \\
\hline Well differentiated & $4286(9.9)$ & $2468(11.8)$ & \\
\hline Moderately differentiated & $30,042(69.7)$ & $14,719(70.2)$ & \\
\hline Poorly/undifferentiated & $8769(20.3)$ & $3770(18.0)$ & \\
\hline \multicolumn{3}{|l|}{ Pathologic stage group, n (\%) } & $<0.001^{2}$ \\
\hline Missing & 2020 & 1196 & \\
\hline Stage 1 & $9474(22.3)$ & $5485(26.8)$ & \\
\hline Stage 2 & $18,075(42.6)$ & $8110(39.7)$ & \\
\hline Stage 3 & $14,848(35.0)$ & $6854(33.5)$ & \\
\hline \multicolumn{3}{|l|}{ Regional nodes examined } & $<0.001^{\mathrm{a}}$ \\
\hline No. & 44,264 & 21,558 & \\
\hline Mean (SD) & $20.3(11.4)$ & $15.7(9.4)$ & \\
\hline Median & 18.0 & 14.0 & \\
\hline Q1, Q3 & $13.0,25.0$ & $10.0,20.0$ & \\
\hline Interquartile range & $(12.0)$ & $(10.0)$ & \\
\hline \multicolumn{3}{|c|}{ Nodes examined (categorized), n (\%) } & $<0.001^{\mathrm{b}}$ \\
\hline Missing & 153 & 87 & \\
\hline 0-11 nodes examined & $7174(16.2)$ & $6669(30.9)$ & \\
\hline $12+$ nodes examined & $37,090(83.8)$ & $14,889(69.1)$ & \\
\hline \multicolumn{4}{|c|}{ Any nodes positive (among those with at least 1 node examined), $\mathrm{n}(\%)$} \\
\hline Missing & 24 & 11 & \\
\hline No & $29,319(66.6)$ & $14,483(68.1)$ & \\
\hline Yes & $14,689(33.4)$ & $6798(31.9)$ & \\
\hline \multicolumn{3}{|c|}{ Regional nodes positive (among those with at least 1 node examined) } & $<0.001^{\mathrm{a}}$ \\
\hline No. & 44,004 & 21,277 & \\
\hline Mean (SD) & $1.1(2.7)$ & $1.1(2.6)$ & \\
\hline Median & 0.0 & 0.0 & \\
\hline Q1, Q3 & $0.0,1.0$ & $0.0,1.0$ & \\
\hline Interquartile range & $(1.0)$ & $(1.0)$ & \\
\hline \multicolumn{3}{|l|}{ Surgical margins, n (\%) } & $0.029^{b}$ \\
\hline Missing & 346 & 157 & \\
\hline No residual disease & $42,388(96.2)$ & $20,741(96.5)$ & \\
\hline Residual disease & $1683(3.8)$ & $747(3.5)$ & \\
\hline \multicolumn{3}{|l|}{ Chemotherapy, n (\%) } & $<0.001^{\mathrm{b}}$ \\
\hline Missing & 2538 & 1199 & \\
\hline No chemotherapy received & $29,103(69.5)$ & $14,781(72.3)$ & \\
\hline Chemotherapy received & $12776(30.5)$ & $5665(27.7)$ & \\
\hline
\end{tabular}

aWilcoxon rank-sum test.

${ }^{b}$ Chi-square test.

Although numerous retrospective series have reported on the feasibility and safety of the laparoscopic approach, ${ }^{7,12}$ few series have compared outcomes based on the extent of surgical resection. Milone et $\mathrm{al}^{13}$ recently published a meta-analysis of 5 retrospective trials involving 11,687 patients, investigating short- and long-term outcomes (5-year disease-free survival, recurrence) according to the extent of resection (extended colectomy vs transverse colectomy). Aligned with our findings, no difference in short-term outcomes and survival was observed, whereas the number of harvested lymph nodes was higher after extended resections. The present study found a near $7 \%$ poorer 5-year survival when transverse colon cancer was approached by extended colectomy. More detailed subgroup analysis revealed that this survival difference was mainly related to mid transverse cancers and to locally advanced (stage III) cancers, where the choice of procedure may be particularly challenging.

Chong et $\mathrm{al}^{9}$ investigated extended vs segmental colectomy for transverse colon carcinoma in a cohort of 1066 patients. Extended colectomy was performed in over 70\% of procedures. No OS difference was found between the 2 approaches after propensity score matching of 254 cases. The authors reported survival rates of $87 \%$ (extended) and $84 \%$ (segmental) at 5 years, which was considerably higher than in the present study.

Guan et $\mathrm{al}^{3}$ analyzed data of 10,344 patients with transverse colon cancer from the Surveillance, Epidemiology, 
TABLE 3. Outcomes among procedure types (diagnosed 2004-2014)

\begin{tabular}{lcc} 
Variable & Extended colectomy $(n=39,956)$ & Segmental colectomy $(n=19,539)$ \\
\hline Thirty-day mortality, $\mathrm{n}(\%)$ & & 164 \\
Missing & 329 & $18,715(96.6)$ \\
Alive & $38,251(96.5)$ & $660(3.4)$ \\
Death & $1376(3.5)$ & 227 \\
Ninety-day mortality, $\mathrm{n}(\%)$ & & $0.68^{\mathrm{a}}$ \\
Missing & 480 & $18,248(94.5)$ \\
Alive & $37,236(94.3)$ & $1064(5.5)$ \\
Death & $2240(5.7)$ & 17,994 \\
Surgical inpatient stay (among those who were discharged) & & $7.1(6.5)$ \\
No. & 36,744 & 6.0 \\
Mean (SD) & $7.4(7.0)$ & $4.0,8.0$ \\
Median & 6.0 & $(0.5-148.0)$ \\
Q1, Q3 & $4.0,8.0$ & $<0.001^{\mathrm{b}}$ \\
Range & $(0.5-168.0)$ & 295 \\
Readmission within 30 days of surgical discharge (among & those who were discharged) & $16,285(92.0)$ \\
Missing & 543 & $962(5.4)$ \\
Not readmitted & $32,988(91.1)$ & $415(2.3)$ \\
Unplanned readmission & $2172(6.0)$ & $37(0.2)$ \\
Planned readmission & $970(2.7)$ & $0.0050^{\mathrm{a}}$ \\
Planned and unplanned readmission & $71(0.2)$ & \\
\hline
\end{tabular}

${ }^{a}$ Chi-square test.

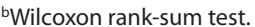

and End-Results (SEER) database. A lower median number of harvested lymph nodes was described for segmental resection (14.3 vs 19.9) but was not included in survival analysis or inserted in the multivariable model. Five-year cancer-specific survival was $67 \%$ for patients undergoing extended colectomy and $67 \%$ for patients undergoing segmental resection. Our NCDB analysis revealed similar rates with respect to OS for the 2 surgical approaches, showing little or no clinical relevance (66.84\% and $67.21 \%)$. Even though NCDB and SEER both represent validated data registries, some important differences exist. National Cancer Database is a hospital-based database covering approximately $30 \%$ of all the medical facilities in the United States (CoC accreditation), whereas SEER is a population-based database and inclusion is based on geographic location, aiming to depict cancer care across the diverse US population. As a result, relevant differences can be found in the distribution of patients' age, sex, and race. Moreover, although both registries provide data on overall survival, cancer-specific survival can be determined only by SEER database. ${ }^{14}$

Despite a lack of survival benefit associated with extended resection, which may be related to the higher morbidity of a larger resection, most surgeons seem to prioritize this approach. ${ }^{15}$ Reasons for this may be related to the more standardized approach to a formal right or left hemicolectomy compared with the atypical and potentially more challenging approach to a segmental resection. ${ }^{16}$

Although some series argue that the number of harvested lymph nodes is not as important as the number of positive lymph nodes for staging and prognosis, ${ }^{17}$ previous evidence and current guidelines consider the number of retrieved lymph nodes to be a reliable surrogate of surgical quality. ${ }^{18}$ Moreover, extent of lymphadenectomy is still a matter of debate, because it is unclear if a high vascular tie with D3 lymph nodes dissection provides a survival benefit. ${ }^{19-23}$ Our study identified the number of harvested lymph nodes as an independent predictive factor of survival for all transverse cancer sites and in advanced stage tumors. For both surgical approaches, the median number of analyzed lymph nodes was higher than the minimum required as suggested by the National Comprehensive Cancer Network guidelines on colon cancer. ${ }^{24}$ Although $30.9 \%$ of segmental resections did not meet these standards, this did not translate into worse survival. Specific reasons for this finding are likely multifactorial and cannot be identified through this series due to inclusion of a large variety of centers bearing a risk of interobserver bias and the long study period with evolving guideline recommendations.

There are several limitations to this study related to its retrospective nature and to limitations of NCDB data in general. For the purpose of this study, hepatic and splenic flexure cancers were used as surrogates for proximal and distal transverse cancer. This approach was chosen because these locations are not further specified in the NCDB data set. Results thus need to be interpreted with caution, for hepatic flexure cancers in particular, where extended right colectomy is considered the standard approach. National Cancer Database represents a prospectively maintained data set and is subject to periodic quality control, auditing, and training. Institutions are expected to provide a 90\% 5-year follow-up to meet CoC accreditation. Despite this effort, it is not possible to account for missing data. Furthermore, NCDB provides neither cancer-specific mortality nor data on recurrence. Modifications in data 


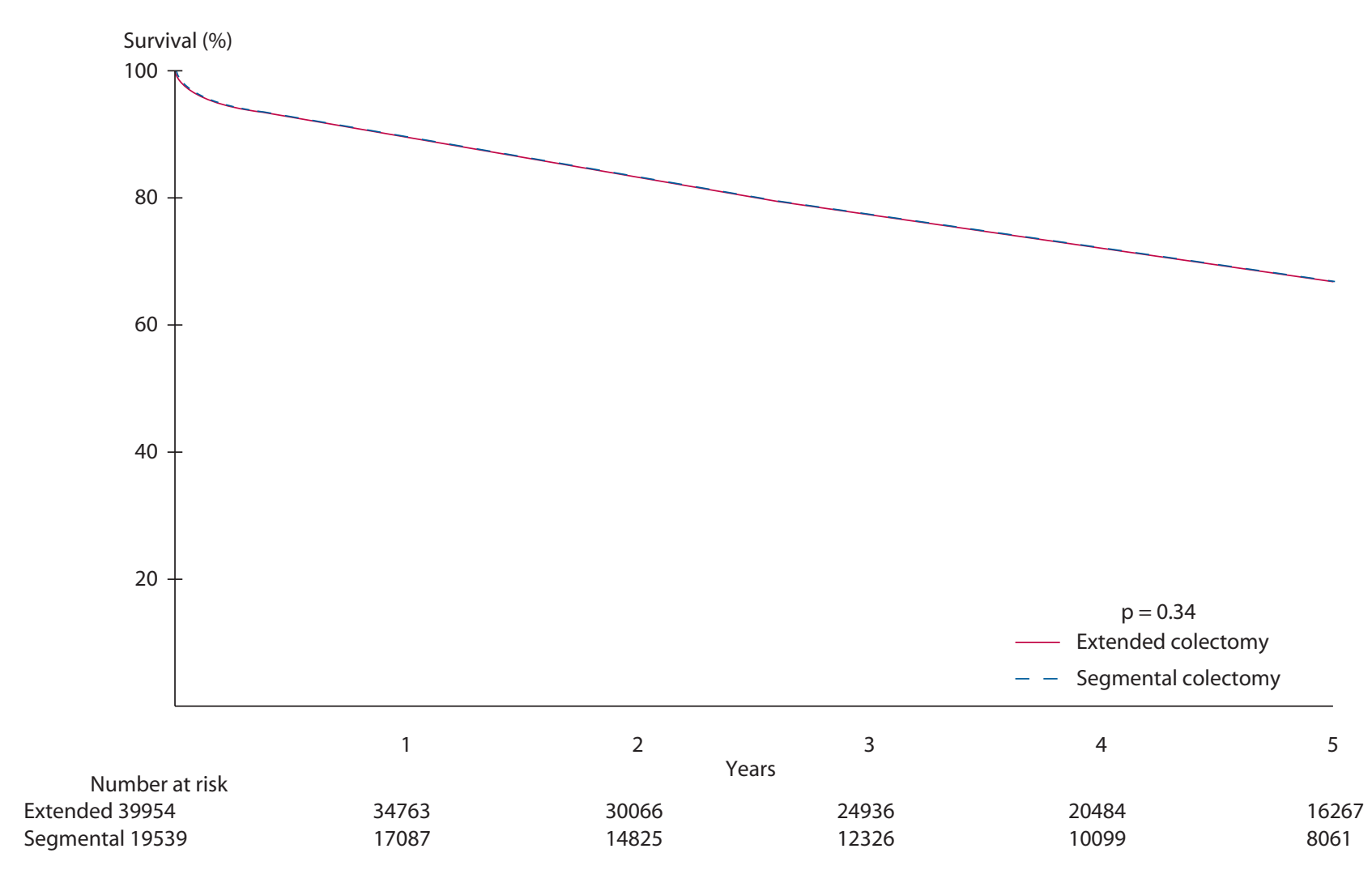

\begin{abstract}
Extended 39954
\end{abstract}
Segmental 19539

FIGURE 2. Kaplan-Meier (KM) curves for survival. Extended colectomy vs segmental colectomy.

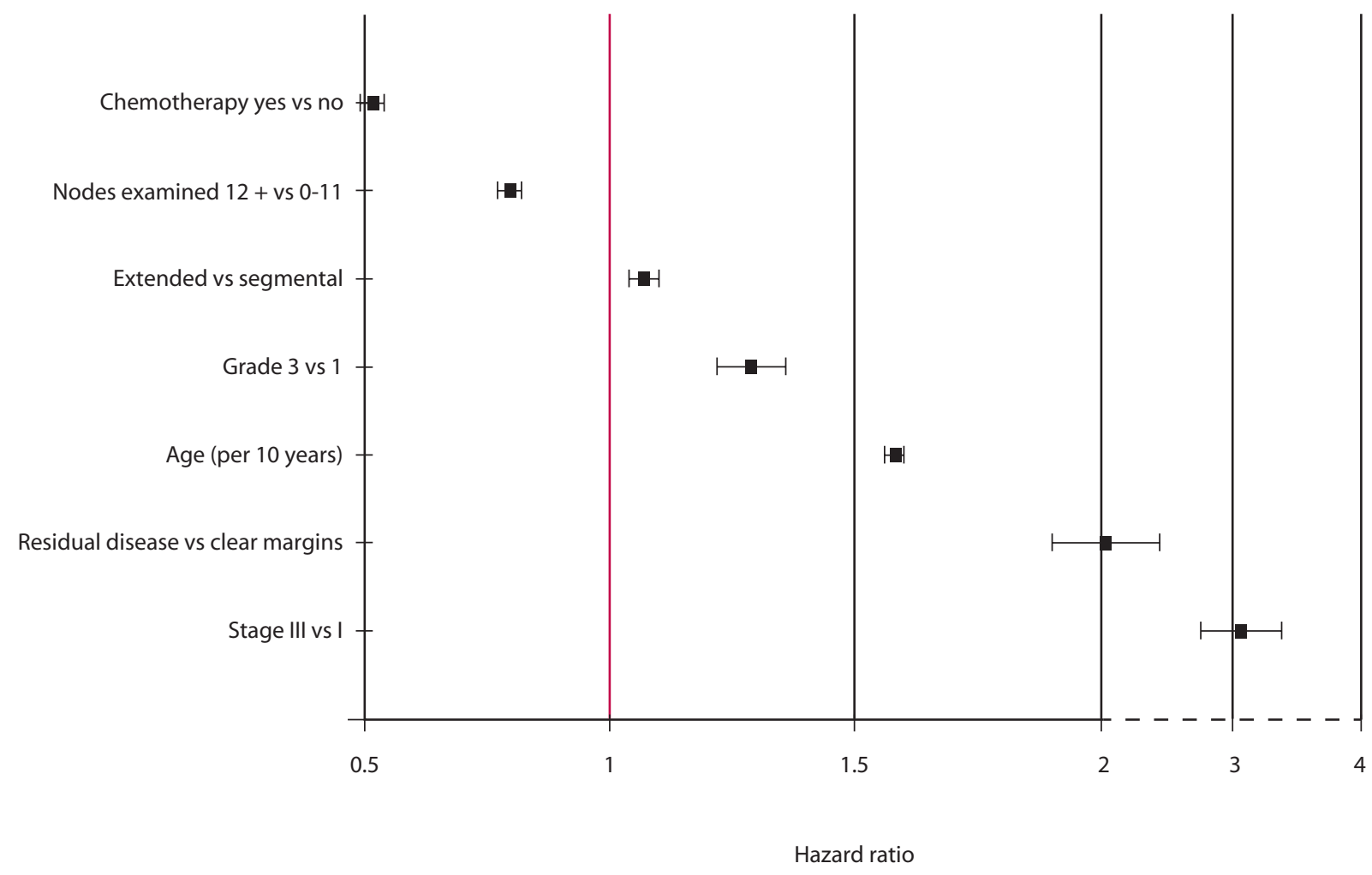

FIGURE 3. Multivariable Cox proportional hazards model for survival (overall patients). 


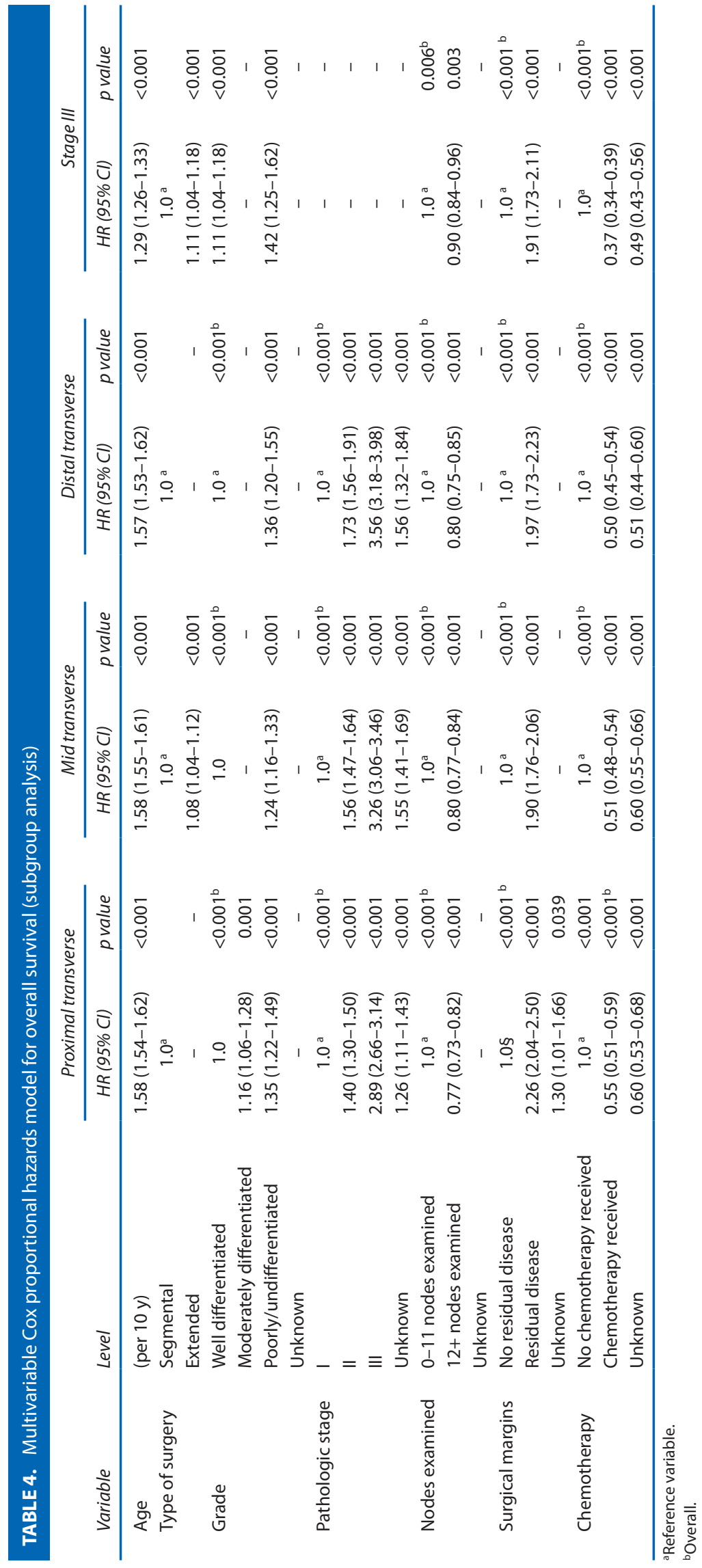


acquisition or assessment occurred over time. This was addressed by specific focusing on newly diagnosed transverse cancers with respective concordant American Joint Committee on Cancer staging classifications and singular TNM items. Although a large nationwide data set such as NCDB is useful to analyze survival trends, the results need to be interpreted with caution.

\section{CONCLUSIONS}

In conclusion, performing an extended colectomy does not provide a survival advantage in comparison with segmental resection, according to this national large-scale study. On the contrary, extended colectomy was associated with slightly poorer survival in mid transverse cancers and locally advanced tumors. Appropriate margins and adequate lymph node harvest as oncological core principles seem to be more important than the surgical approach itself, which should be chosen according to both surgeon's preference and ability with either approach.

\section{REFERENCES}

1. Stelzner S, Hohenberger W, Weber K, West NP, Witzigmann H, Wedel T. Anatomy of the transverse colon revisited with respect to complete mesocolic excision and possible pathways of aberrant lymphatic tumor spread. Int J Colorectal Dis. 2016;31:377-384.

2. Kim NK, Kim YW, Han YD, et al. Complete mesocolic excision and central vascular ligation for colon cancer: principle, anatomy, surgical technique, and outcomes. Surg Oncol. 2016;25:252-262.

3. Guan X, Zhao Z, Yang M, et al. Whether partial colectomy is oncologically safe for patients with transverse colon cancer: a large population-based study. Oncotarget. 2017;8:93236-93244.

4. van Rongen I, Damhuis RA, van der Hoeven JA, Plaisier PW. Comparison of extended hemicolectomy versus transverse colectomy in patients with cancer of the transverse colon. Acta Chir Belg. 2013;113:107-111.

5. Gouvas N, Agalianos C, Papaparaskeva K, Perrakis A, Hohenberger W, Xynos E. Surgery along the embryological planes for colon cancer: a systematic review of complete mesocolic excision. Int J Colorectal Dis. 2016;31:1577-1594.

6. Wray CM, Ziogas A, Hinojosa MW, Le H, Stamos MJ, Zell JA. Tumor subsite location within the colon is prognostic for survival after colon cancer diagnosis. Dis Colon Rectum. 2009;52:1359-1366.

7. Athanasiou CD, Robinson J, Yiasemidou M, Lockwood S, Markides GA. Laparoscopic vs open approach for transverse colon cancer. A systematic review and meta-analysis of short and long term outcomes. Int J Surg. 2017;41:78-85.

8. Leijssen LGJ, Dinaux AM, Amri R, Kunitake H, Bordeianou LG, Berger DL. A transverse colectomy is as safe as an extended right or left colectomy for mid-transverse colon cancer. World J Surg. 2018;42:3381-3389.

9. Chong CS, Huh JW, Oh BY, et al. Operative method for transverse colon carcinoma: transverse colectomy versus extended colectomy. Dis Colon Rectum. 2016;59:630-639.
10. American College of Surgeon National Cancer Database. CoC quality of care measures 2020 surveys. Published 2016. Updated August 19, 2020. https://www.facs.org/quality-programs/cancer/ncdb/qualitymeasurescocweb Accessed August 2020.

11. North American Association of Central Cancer Registries (NACCR). Implementation Guidelines and Recommendation. https://www.naaccr.org/wp-content/uploads/2020/10/2021Implementation-Guidelines_20201009.pdf. Published 2020.

12. Fernández-Cebrián JM, Gil Yonte P, Jimenez-Toscano M, Vega L, Ochando F. Laparoscopic colectomy for transverse colon carcinoma: a surgical challenge but oncologically feasible. Colorectal Dis. 2013;15:e79-e83.

13. Milone M, Manigrasso M, Elmore U, et al. Short- and long-term outcomes after transverse versus extended colectomy for transverse colon cancer. A systematic review and meta-analysis. Int $J$ Colorectal Dis. 2019;34:201-207.

14. Boffa DJ, Rosen JE, Mallin K, et al. Using the National Cancer Database for outcomes research: a review. JAMA Oncol. 2017;3:1722-1728.

15. Odermatt M, Siddiqi N, Johns R, et al. Short- and long-term outcomes for patients with splenic flexure tumours treated by left versus extended right colectomy are comparable: a retrospective analysis. Surg Today. 2014;44:2045-2051.

16. Matsuda T, Sumi Y, Yamashita K, et al. Optimal surgery for midtransverse colon cancer: laparoscopic extended right hemicolectomy versus laparoscopic transverse colectomy. World J Surg. 2018;42:3398-3404.

17. Mathis KL, Green EM, Sargent DJ, Delaney C, Simmang CL, Nelson H. Surgical quality surrogates do not predict colon cancer survival in the setting of technical credentialing: a report from the prospective COST trial. Ann Surg. 2013;257:102-107.

18. Dillman RO, Aaron K, Heinemann FS, McClure SE. Identification of 12 or more lymph nodes in resected colon cancer specimens as an indicator of quality performance. Cancer. 2009;115:1840-1848.

19. Olofsson F, Buchwald P, Elmståhl S, Syk I. No benefit of extended mesenteric resection with central vascular ligation in right-sided colon cancer. Colorectal Dis. 2016;18:773-778.

20. Bertelsen CA, Neuenschwander AU, Jansen JE, et al; Danish Colorectal Cancer Group. Disease-free survival after complete mesocolic excision compared with conventional colon cancer surgery: a retrospective, population-based study. Lancet Oncol. 2015;16:161-168.

21. Søndenaa K, Quirke P, Hohenberger W, et al. The rationale behind complete mesocolic excision (CME) and a central vascular ligation for colon cancer in open and laparoscopic surgery: proceedings of a consensus conference. Int $J$ Colorectal Dis. 2014;29:419-428.

22. Ueki T, Nagai S, Manabe T, et al. Vascular anatomy of the transverse mesocolon and bidirectional laparoscopic D3 lymph node dissection for patients with advanced transverse colon cancer. Surg Endosc. 2019;33:2257-2266.

23. Reddavid R, Esposito L, Evangelista A, Sofia S, Degiuli M. Non-anatomical colonic resections: splenic flexure and transverse colectomy. Central vascular ligation is crucial for survival. Minerva Chir. 2019;74:176-186.

24. NCCN Guidelines for Patients: Colon Cancer. Version 4.2018. National Comprehensive Cancer Network, Inc. 2018. 